\title{
A NEW BEE OF THE GENUS EMPHOR.
}

\author{
By T. D. A. Cockerell, \\ University of Colorado.
}

Mr. C. T. Brues has kindly sent me three females of a species of Emphor, collected by Miss Louise Nichols at Cape May Pt., N. J., Aug. 25, 1912. To my surprise, they are not E. bombiformis but represent a new species.

\section{Emphor fuscojubatus sp. nov.}

․ Like $E$. bombiformis (a cotype from Georgia compared) but differing as follows: hair of vertex dark rufofuscous, instead of being ochreous like that of the thorax; hair of thorax paler, not so red; hair of middle of front fuscous instead of whitish; scape not red at apex; third submarginal cell conspicuously longer; hind margin of first abdominal segment narrowly pale and pellucid; wings perhaps rather paler.

This is probably the Emphor bombiformis of Smith's New Jersey list.

\section{SOME OBSERVATIONS ON THE NESTING HABITS OF THE MINING BEE, EMPHOR FUSCOJUBATUS Ckll.}

\section{By M. Louise Nichols.}

These observations were made during the last week of August, 1912, at Cape May Point, N. J., by Mr. Reynold A. Spaeth and myself. The bees collected were thought at first to be Emphor bombiformis Cress., but a closer examination by Prof. T. D. A. Cockerell revealed the fact that they were sufficiently unlike $\boldsymbol{E}$. bombiformis to be classed as a new species, named by Prof. Cockerell Emphor fuscojubatus, and differing from the other species chiefly in the color of the hair on various parts of the body and in the greater size of the third submarginal cell of the wing. It is a member of the family Apidæ.

By the side of a road, for a distance of about one eighth of a mile, in soil consisting of a mixture of clay, sand and pebbles, numerous nest openings were discovered and between about ten A. M. and four P. M. many bees flying in and out. The nest is begun as a semicircular depression, the soil being moistened by a fluid from 
the mouth, loosened by the mandibles, and ejected sidewise by the first and second pairs of legs. As the depression increases in depth, it is surrounded by a wall of the moistened earth, reaching a height of about one centimetre, the posterior end of the abdomen being used as a trowel in its construction.

At frequent intervals the bee stops work, and after an absence of thirty seconds or so, returns. Our curiosity aroused as to the reason for these frequent excursions, we followed one individual in her flight and were led to a small pond about seventy-five yards away. Here numerous bees were discovered floating on the surface with legs outstretched, presumably sucking up into their crops a supply of water for use in making the nest. By its aid the clayey soil is formed into pellets, passed under the body probably by means of the tibianl spines and kicked out at the entrance by a sudden jerk of the last pair of legs, most comical in the impression it produces of business like intention. The force of the jerk is often considerable, as the pellets are thrown several inches from the mouth of the nest.

Less than twenty-four hours is occupied in the construction of the nest. One begun at twelve thirty P. M. was three inches deep at four, the same day. The following morning, between sixthirty and seven, the bee was observed entering, her hind legs and body heavily laden with flocculent masses of pollen. She remained within for one minute, presumably packing the pollen, came out and was gone for five to six minutes, returning again laden with pollen. Sometimes the load is so superabundant that fragments of it will be dropped on the ground near the entrance. If the weather were cloudy, the time was lengthened, more than ten minutes being required for collection of the pollen. After a final trip she remained within for a longer time, i. e., twenty minutes, possibly occupied in laying an egg. The nest is completed by gnawing away the raised rim of earth about the opening. Usually the surrounding pellets are also drawn in by the first pair of legs, the earth thus filling and closing the entrance. A nearly circular depression, however, marks the site, for the earth is not filled in level with the soil surface.

On digging the earth away from the nest cavity, a considerable mass of fermenting pollen of sour smell was found and on it a single, slightly curved egg, six mm. in length. The pollen is collected, 
apparently only in the early morning hours, for no bees were seen bearing pollen in the middle or latter part of the day. Many plants were blooming in the vicinity, wild Compositæ and Leguminosæ, also cultivated sweet peas and morning glories, but none of them were visited by the bees. Since the heavy, sticky masses brought back by them resembled in appearance the pollen of Hibiscus moschatus, which grew abundantly in the swamps not far away, it was suspected that this plant might be the source of supply. A comparison under the microscope of Hibiscus pollen with some taken from a nest proved this to be the case.

Although the behavoir of the bees corresponds in general to the foregoing description, some variation was observed. As is often the case with solitary wasps, nests may be begun and abandoned before completion. The wall of earth around the entrance is more carefully built in some nests than in others, and the distance to which the pellets are thrown also varies. Individual differences in the ease with which the nest was recognized were also noticed. Some fly with astonishing directness and rapidity to the opening, while others alight at the wrong spot and appear confused. Bees sometimes enter nests not their own, and, on discovering the mistake, back hurriedly out. Before emerging it is usual for the insect to stop a moment at the opening, moving the head from side to side as if reconnoitring. Slight movement or noise in the neighborhood will cause her to jerk back into the nest, but after a short interval, she slowly reappears, again reconnoitres and flies off. Individuals differ in this respect also; some appear more timid than others.

On Nov. 29, I again visited the place, in order to determine if possible how the bees passed the winter. No trace remaining of the depressions marking the site of the nests, I was obliged to dig at random. The quest proved not entirely fruitless and three cocoons were obtained containing larvæ. The cocoon is made of densely woven silk entangling many left over pollen grains and lined with a brownish varnish-like substance, well adapted to keep out the dampness. The largest of the three measures a little over two centimetres (about twenty three $\mathrm{mm}$. by thirteen, the smallest about thirteen $\mathrm{mm}$. in each dimension and the third about sixteen $\mathrm{mm}$. by thirteen $\mathrm{mm}$. This last was broken in removing it from the soil. It contained a small larva not quite a centi- 
metre long. The remaining two cocoons were buried in soil contained in a tin box and when next examined, Dec. 28, the larva within the larger cocoon was found dead. The small head, bearing distinct black jaws was bent under the body as was also the posterior end. The body nearly equalled in length the longer diameter of the cocoon. As the male of the closely related species, $E$. bombiformis is smaller than the female, the most probabl explanation of the difference in the size of the cocoons is that the larger ones contain females, the smaller ones males.

Since writing the foregoing, I have discovered in the Journal of the N. Y. Entomological Society for Dec. 1911, an article entitled "Contributions toward the Life History of Emphor bombiformis," by John A. Grossbeck, a record of observations made at Arlington, N. J. The account does not in all respects correspond to the observations made on $E$. fuscojubatus, and as it would be interesting to know whether the two behave differently because they are different species or because of difference in the environment, I think, it worth while to call attention to the nature of the discrepancies.

Grossbeck describes the bee as beginning the nest by digging with the fore legs in a thin layer of sod, brushing the fragments away with the hind legs and turning around constantly. When the hole is one-half an inch deep, soil is reached and a different method of working begun. The soil is now moistened with saliva, small pieces bitten off with the mandibles, where, with the assistance of the abdomen, it is placed at the entrance. No doubt the difference in the manner of beginning to dig is due to the difference in the character of the soil, for in the location chosen by E. fuscojubatus there was practically no sod and the bee commenced to work at once on a sandy surface.

The bees at Cape May Point seemed but little disturbed by our presence at any time, except that when reconnoitring at the mouth of the nest, a sudden movement or noise would cause a hasty retreat. We were able to sit quietly very close to the opening without interfering with their comings and goings. On the other hand, the bees at Arlington showed great commotion, flew wildly about, buzzed loudly and were so reluctant to enter their burrows that a group of a little more than twelve were increased to about thirty. Quiet ensued in about five minutes and later in the day 
they were not disturbed by human presence. The observer remained, however, about two feet away from the nest openings.

More than once, also, Grossbeck noticed bees showing animosity toward each other. On one occasion when a pollen-laden bee returned to find its burrow already occupied by another, also pollen-bearing, there followed a really dramatic episode. Both came out hurriedly, buzzed around, clenched, rolled on the ground, separated and were then lost to sight. Presently one returned, presumably the rightful owner, and rapidly removed three loads of pollen, two of which were dropped not far from the entrance and the third was carried farther away. The colony of E. fuscojubatus, on the contrary, so far as we could tell lived together, mutually harmonious, yet independent. It is well known that some strains of Apis mellifica show much greater excitability and pugnacity than others and it is quite possible that, of these two closely related species, one is more readily moved to fear or wrath than the other.

Exactly at what hour $E$. bombiformis was seen carrying pollen is not stated, but it is to be supposed from the following that it was in the afternoon. Referring to the greater ease with which pollenladen bees find the entrance, Grossbeck remarks "There was no uncertainty displayed as in the morning hours." This is strikingly different from the habit of E. fuscojubatus, which was to collect pollen only in the early morning.

It seems likely that the reason why pollen-laden bees fly so directly to their burrows is that, in the course of frequent trips to and fro during the making of the nest, they have gained a more thorough familiarity with the surroundings. As far as I remember, this directness of flight was not confined to bees bearing pollen.

On Aug. 22, Grossbeck saw bees on a roadside puddle, but was not sure whether they actually lapped up the water or not. A rather strong wind was blowing at the time, by which the insects were constantly swept across the puddle. "They seemed to fly back to the windward side when blown across, for mere sport." I think there can be no doubt that the bees actually do take up the water, because of the regularity of their visits to the pond or puddle, the time that they spend there and the quantity of fluid coming from the mouth, used to moisten the earth and form pellets. ${ }^{1}$

\footnotetext{
1 F. Knab reports seeing $E$. bombiformis at the edge of a marsh on the outskirts of Washington, alighting on the surface of the water. They remained usually about 10 sec., the proboscis in contact with the water.-Proc. Wash. Ent. Soc., 1911, p. 170.
} 
Perhaps the most striking difference in the habits of the two species is indicated by the fact that the eggs and larvæ obtained by Grossbeck were dug from open burrows and nothing was seen like a covered burrow. Emphor fuscojubatus very plainly makes use of the turret earth and even the ejected pellets for covering the nest not long after oviposition, leaving, however, a nearly circular depression somewhat like the impression of a finger tip in the sand.

That no bees were seen at Arlington after Sep. 3 may very well have been due to unfavorable weather conditions. At Cape May Point some were still active during the first week of September, but how much longer I do not know.

The death rate of the larvæ must be high, for from twenty-one cocoons preserved by Grossbeck he reports as emerging only one male and six females. This took place between July 11 and July 20, although on July 21 no bees were seen in the vicinity of the nesting site. Probably the time of emerging from the cocoon is nearly the same for $E$. fuscojubatus, although $I$ have as yet made no observations on this point.

\section{ANTS COLLECTED IN GEORGIA BY DR. J. C. BRADLEY AND MR. W. T. DAVIS.}

\section{By William Morton Wheeler.}

The following list is compiled from a large collection of ants made in different parts of Georgia by Dr. J. C. Bradley and a smaller collection made by Mr. W. T. Davis in a more restricted area. I have indicated the names of these collectors by their initials for each locality.

\section{Family Formicide. Subfamily Ponerince.}

1. Stigmatomma pallipes Haldem.-Clayton (J. C. B.); Black Rock Mt., Rabun Co. (W. T. D.).

2. Ponera trigona Mayr var. opacior Forel.-Gainesville and Billy's Island, Okefenokee Swamp (J. C. B.).

3. Ponera opaciceps Mayr.-St. Simon's Island (J. C. B.).

4. Ponera coarctata Latr. subsp. pennsylvanica Buckley.-Spring Creek, Burton, Thalman and Atlanta (J. C. B.). 

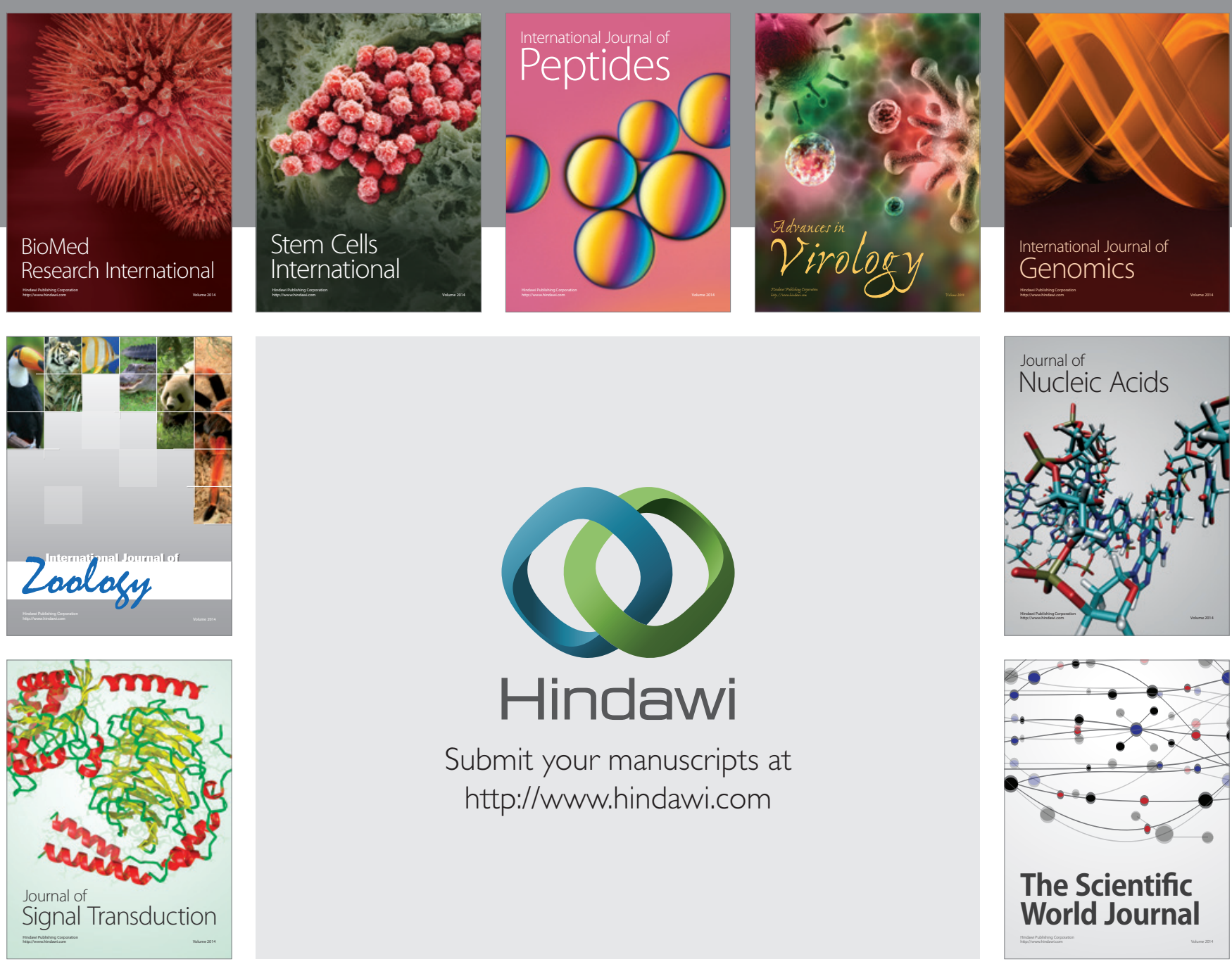

Submit your manuscripts at

http://www.hindawi.com
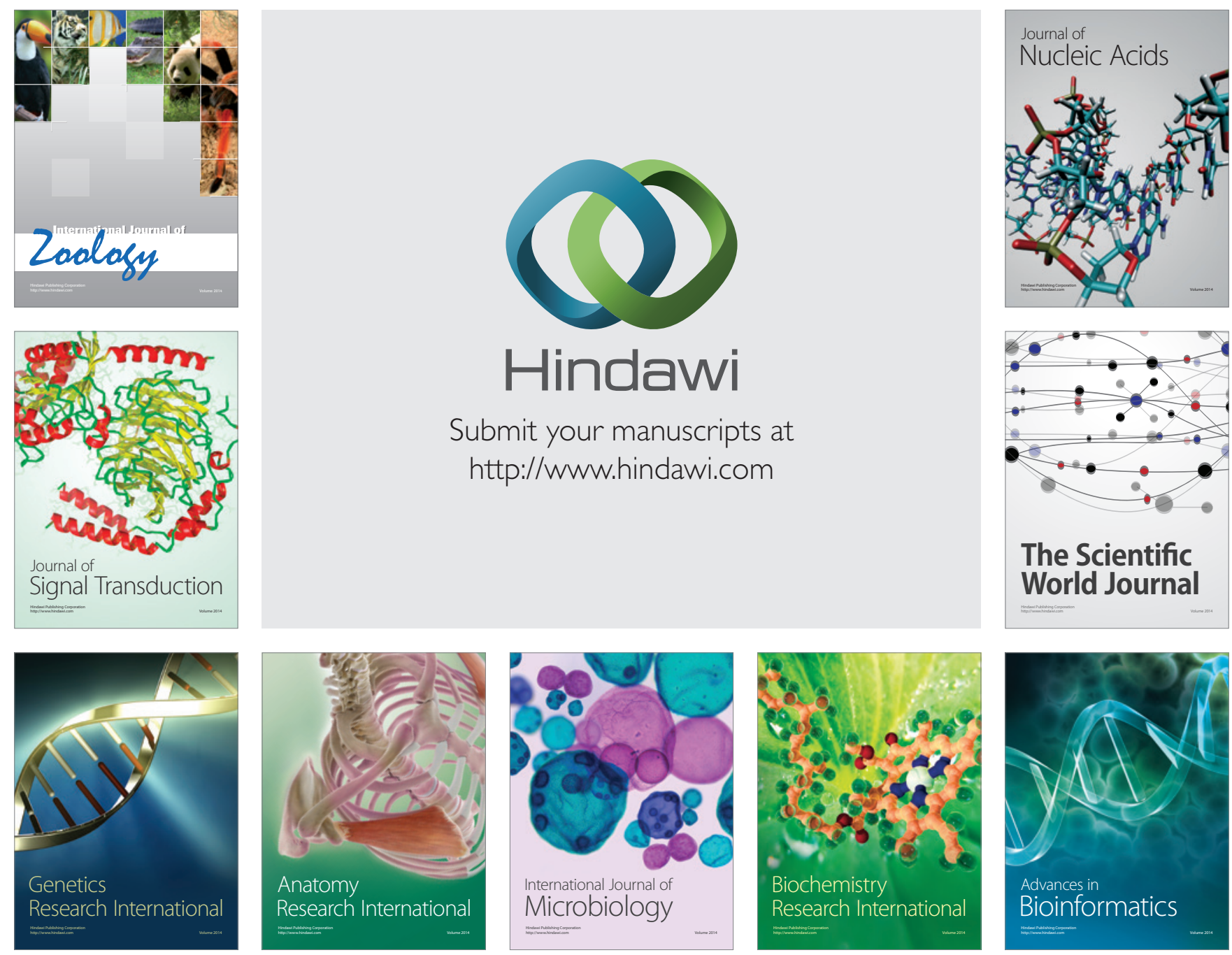

The Scientific World Journal
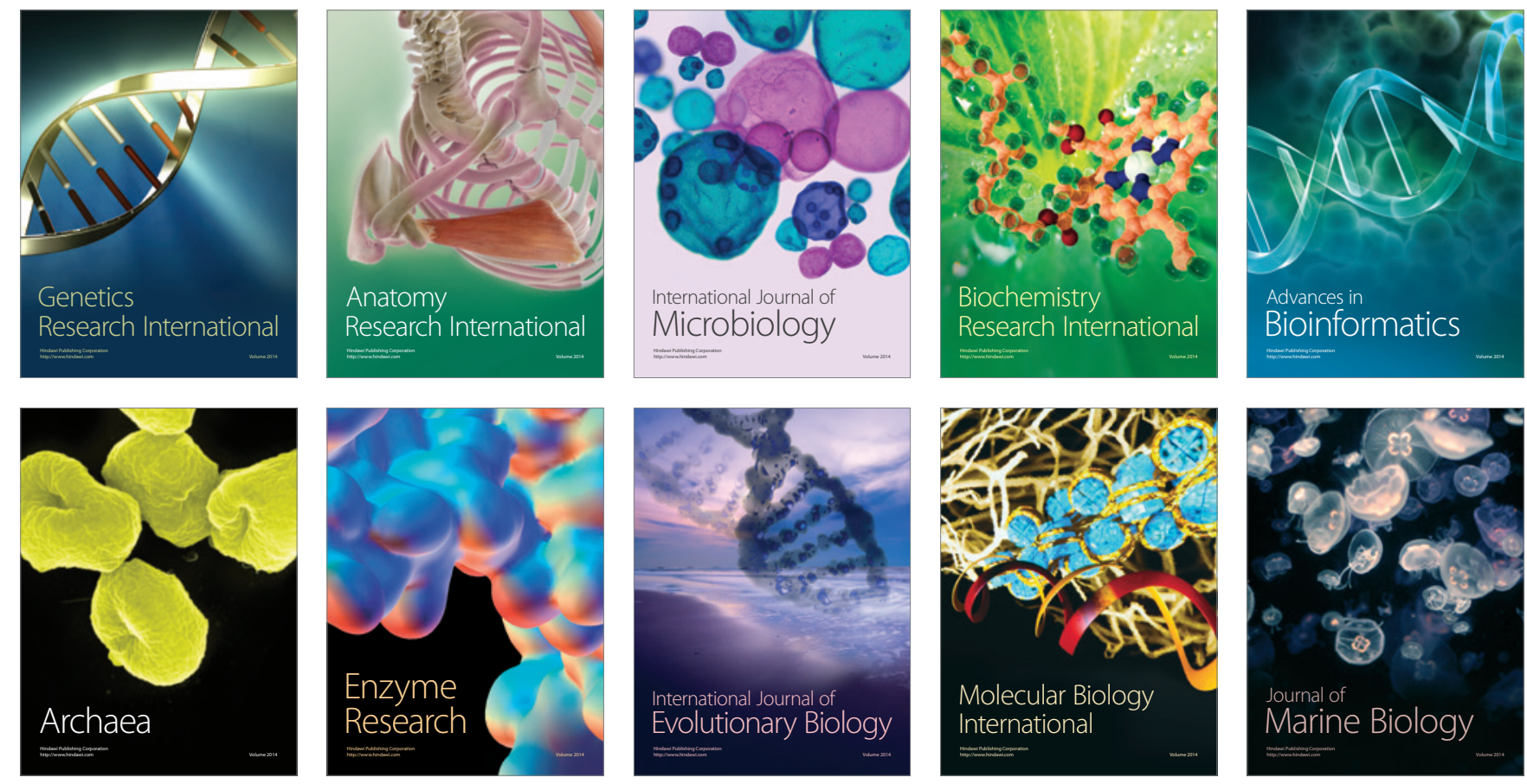